Journal of Molecular Structure (Theochem), 110 (1984) 277-291

Elsevier Science Publishers B.V., Amsterdam - Printed in The Netherlands

\title{
THEORETICAL DETERMINATION OF MOLECULAR STRUCTURE AND CONFORMATION
}

Part 12. Puckering of 1,3,5-cycloheptatriene, $1 \mathrm{H}$-azepine, oxepine and their norcaradienic valence tautomers

\author{
DIETER CREMER and BERNHARD DICK
}

Lehrstuhl für Theoretische Chemie, Universität Köln, D-5000 Köln 41 (West Germany)

\section{DINES CHRISTEU}

Institut für Physikalische Chemie, Universität Tübingen, D-7400 Tübingen 1

(West Germany)

(Received 21 March 1984)

\section{ABSTRACT}

Restricted Hartree-Fock calculations have been carried out for 1,3,5-cycloheptatriene, norcaradiene, $1 \mathrm{H}$-azepine, benzenimine (azanorcardiene), oxepine and benzene oxide (oxanorcaradiene) employing the STO-3G, 4-31G and 6-31G* basis sets. Theoretical geometries, conformations and barriers to ring inversion have been obtained and compared with the available experimental structural data. It has been found that the cyclotrienes possess a boat conformation with a constant admixture of $22 \%$ chair character leading to a flattening of the triene part and $\pi$-electron delocalization typical for a planar polyene. The structural data obtained in this work suggest that cyclic delocalization of either $6 \pi$ (homoaromaticity) or $8 \pi$ electrons (antiaromaticity) is not present in the three cyclotrienes. The former possibility, however, cannot be excluded in the case of the three norcaradienes.

\section{INTRODUCTION}

The structural and conformational features of 1,3,5-cycloheptatriene (CHT, 1) and its valence tautomer norcaradiene $(\mathrm{NCD}, 2)$ have attracted interest from many chemists, in particular from theoretical organic chemists, for more than two decades [1]. Both 1 and 2 can be considered as potential homobenzenes with a partially delocalized $6 \pi$-electron system.

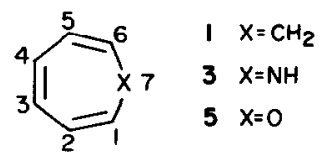

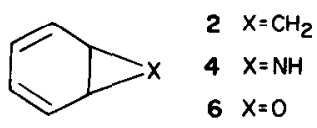

CHT may obtain some aromatic character by 1,6 overlap of $2 p \pi$-orbitals and a homoconjugative closure of the triene part. In NCD, however, interactions between the $\pi$-molecular orbitals ( $\pi-\mathrm{MOs}$ ) of the diene part and the 
Walsh MOs of the three-membered ring can lead to a partial opening of the 1,6 -bond, thus lending it some $\pi$-character. In the extreme of aromatic delocalization of $\pi$-electrons the structures of 1 and 2 will merge to one, namely 7 ,

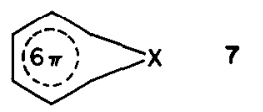

which should correspond to the transition state of the valence tautomerization $\mathbf{1} \rightarrow \mathbf{2}$.

It is also possible that some of the properties of CHT are the result of destabilizing rather than stabilizing $\pi$-electron interactions. Conjugative overlap of the $\pi$-MOs of the triene part with the pseudo- $\pi$-orbital of the $\mathrm{CH}_{2}$ group could establish a potentially antiaromatic $8 \pi$-electron system, which is generally considered to cause destabilization of a cyclopolyene. This possibility becomes even more likely in the case of heterocycloheptatrienes like $1 \mathrm{H}$ azepine $(A Z P, 3)^{a}$ or oxepine $(\mathrm{OXP}, 5)$, which can contribute an electron lone pair to the $\pi$-system. Antiaromatic $8 \pi$-electron delocalization, if present, should become less important with decreasing 1,6 distance. It should vanish in the bicyclic valence tautomers NCD, benzenimine (BI, 4) and benzene oxide $(\mathrm{BO}, 6)$.

Both alternatives of $\pi$-electron delocalization have been discussed in connection with measured properties of CHT [1], AZP [2], and OXP [3]. Attempts have been made to assess the degree of electron delocalization from the observed structural and conformational data of compounds 1, 3 and 5. According to an electron diffraction (ED) and a microwave (MW) investigation of CHT $[4,5]$, the molecule is nonplanar and possesses a boat form. This has been confirmed by X-ray studies of the substituted CHTs [6-9] and AZPs [10-12] shown in Fig. 1. For unsubstituted AZP and OXP no direct structural information is available so far, but spectroscopic evidence is consistent with a boat conformation of these molecules $[2,3]$.

The nonplanar geometry of cyclotrienes 1,3 and 5 may be considered as the result of avoided $8 \pi$-electron delocalization. On the other hand, ring puckering leads to a decrease of the 1,6-distance and, therefore, may enhance homoconjugative interactions. Whether this will guarantee significant homoaromatic stabilization, should depend on the degree of puckering.

As for the byciclic forms 2, 4 and 6 only a few X-ray data of some heavily substituted NCDs [13-15] and BOs [16, 17] have been published (see Fig. 1). Due to the impact of the substituents on the reported geometries it is difficult to make a clear assessment of electron delocalization in the NCD forms on the basis of these data.

The present work has several objectives. First, theoretical geometries for compounds $1-6$ will be presented and compared with the known experi-

${ }^{\text {a}}$ For reasons of simplicity the numbering of atoms in compounds $3-6$ is kept the same as in 1, although this does not conform to IUPAC nomenclature. 


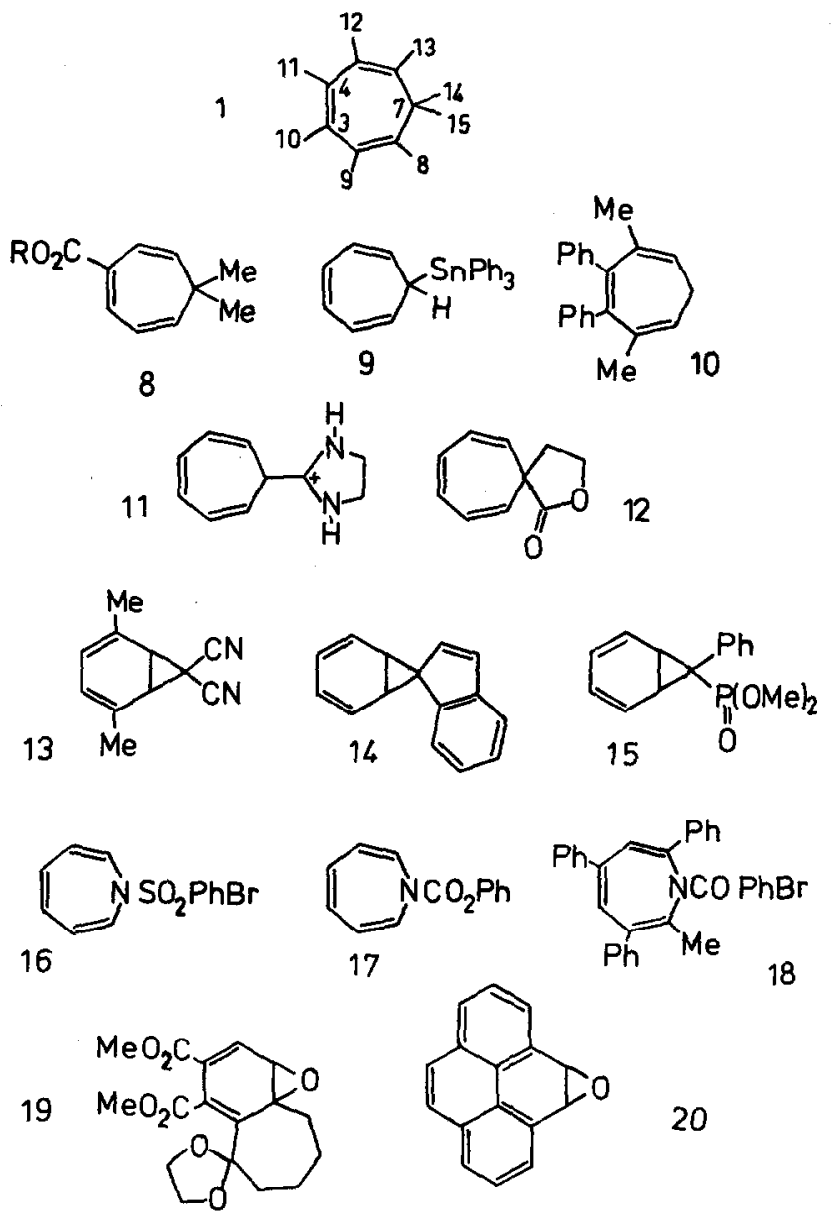

Fig. 1. Substituted cycloheptatrienes, norcaradienes, azepines and benzene oxides ( $8-20)$ investigated by $\mathrm{X}$-ray diffraction.

mental data. Secondly, the conformational features of 1-6 will be analyzed on the basis of ring puckering parameters and barriers to ring inversion. Finally, it will be demonstrated that the assumption of substantial electron delocalization of either 6 or $8 \pi$-electrons is rather speculative in the case of the cyclotrienes 1,3 and 5 but homoaromatic character cannot be excluded for the NCD forms.

The investigation of compounds $1-6$ has been part of a major effort intended to describe valence tautomerizations in cyclopolyenes, in particular bridged [10]- and [14]-annulenes [18]. Since ab initio calculations of the larger annulenes become prohibitively expensive, another objective of this work is to test whether one of the less costly semiempirical methods can be used to obtain reasonable geometries and conformations of larger cyclopolyenes. 


\section{THEORETICAL METHODS}

Two levels of theory have been employed in this work. Explorative calculations have been carried out with the semiempirical MNDO method [19]. This method is known to provide reasonable geometries for hydrocarbons, yet its applicability to large cyclopolyenes has only been tested in isolated cases [20].

In order to obtain ab initio geometries of 1-6, all optimizations have been repeated at the restricted Hartree-Fock ( $\mathrm{RHF}$ ) level of theory employing the minimal STO-3G basis set (basis A) [21]. In these calculations a slightly constrained geometry model with all $\mathrm{CH}$ bonds fixed at standard values [22] has been used.

A more accurate account of the conformational barriers of ring compounds is generally provided by the $4-31 \mathrm{G}(\mathrm{B})$ and $6-31 \mathrm{G}^{*}(\mathrm{C})$ basis set [21]. Thus single point calculations were carried out with $B$ and $C$ at RHF/A geometries.

The degree of nonplanarity of the CHT boat form is usually described by the two folding angles $\alpha$ and $\beta$ defined in Fig. 2. Alternatively, the ring puckering parameters can be used to analyze the conformation of CHT [23, 24 ]. For a seven-membered ring there are two puckering amplitudes, $q_{2}$ and $q_{3}$, and two pseudorotation phase angles, $\phi_{2}$ and $\phi_{3}$. The latter are set to $0^{\circ}$ or $180^{\circ}$ for $C_{\mathrm{s}}$ symmetry of $1-6$. The overall degree of puckering is measured by the total puckering amplitude $Q=\left(q_{2}^{2}+q_{3}^{2}\right)^{1 / 2}$. If the cyclotriene conformation is a pure boat, amplitude $q_{3}$ will also be zero since it describes puckering of the chair form. If, however, $q_{3}>0$, then the ratio
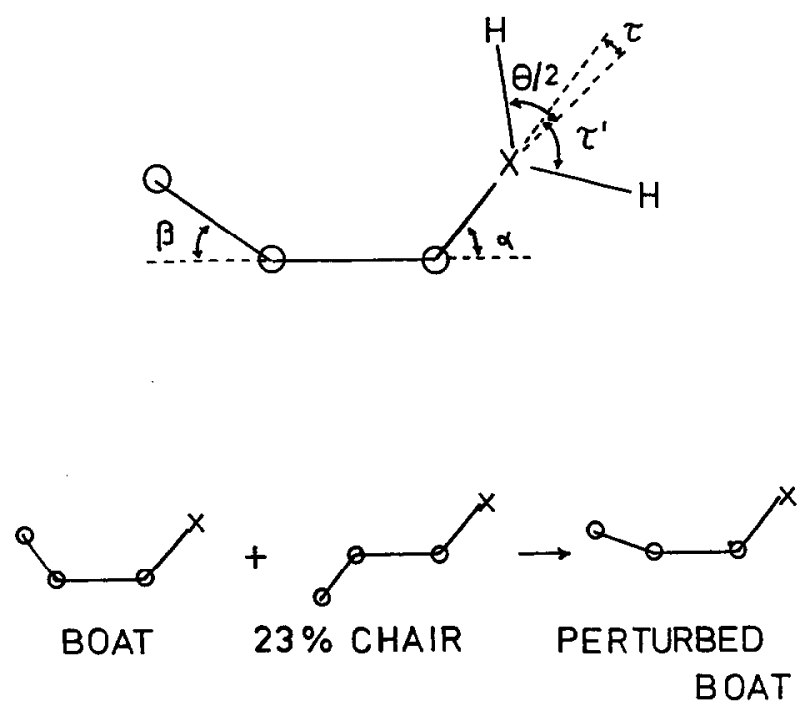

Fig. 2. Definition of conformational parameters. Representation of the actual ring conformation (perturbed boat) as a linear combination of boat and chair form of the sevenmembered ring. 
$\eta_{q}=q_{3} \cos \phi_{2} \cos \phi_{3} /\left(q_{2}+q_{3}\right)$

will describe the amount of chair character admixed with the boat form to yield the actual conformation of the seven-membered ring. The factor cos $\phi_{3}$ indicates whether a chair form $\left(\phi_{3}=0^{\circ}\right)$ or an inverted chair $\left(\phi_{3}=180^{\circ}\right)$ is superposed on the boat $\left(\phi_{2}=0^{\circ}\right)$ or inverted boat form $\left(\phi_{2}=180^{\circ}\right)$. The following relationships hold

$\eta_{q}>0$ and $\alpha>\beta$ for $\phi_{2}=0\left(180^{\circ}\right)$ and $\phi_{3}=0\left(180^{\circ}\right)$;

$\eta_{q}<0$ and $\alpha<\beta$ for $\phi_{2}=0\left(180^{\circ}\right)$ and $\phi_{3}=180^{\circ}\left(0^{\circ}\right)$

The amount of chair character can also be defined using $\alpha$ and $\beta$, e.g. by

$\eta_{\alpha}=(\alpha-\beta) / 2 \alpha$

Similarly,

$$
1-\eta_{\alpha}=(\alpha+\beta) / 2 \alpha=\eta_{\beta}
$$

provides a quantitative measure for the boat character. In general, $\eta_{\alpha} \neq \eta_{q}$ since two different reference planes are used to establish the boat character of the seven-membered ring. The evaluation of the $q$-values is based on the mean plane of the ring $[23,24]$, which is derived from the positions of all ring atoms. The reference plane for the determination of $\alpha$ and $\beta$ is the plane of just four ring atoms, namely, atoms $1,2,5$ and 6 (Fig. 2).

\section{RESULTS}

RHF/A and MNDO geometries of compounds 1-6 are compared in Tables 1 and 2. Table 3 contains a summary of the corresponding conformational parameters. Geometries and energies of the planar transition states for ring inversion are shown in Table 4.

\section{Geometries}

$\mathrm{Ab}$ initio RHF/A and semi-empirical MNDO geometries of compounds 1-6 differ by $0.01-0.03 \AA$ and $1-7^{\circ}$, as can be seen from bond lengths, $r$, and bond angles, $\theta$, of Tables 1 and 2. Deviations are larger for the CHT forms than for the NCD forms. In order to assess the predictive value of the theoretical geometries, some relevant experimental data are listed in Tables 5 and 6. The former contains results of the ED [4] and MW [5] investigation of CHT. The ED analysis published by Traetteberg remains so far the only overall structural determination of the molecules considered in this work. Therefore, it is necessary to take recourse to the structural data of the reference compounds of Table 6 when comparing RHF/A and MNDO geometries. For this purpose we have chosen propane (21), dimethylamine (22), dimethylether (23), trans-1,3-butadiene (24), cyclopropane (25), aziridine (26), and oxirane $(27)[19,25,26]$. 


\section{TABLE 1}

Theoretical geometries for 1,3,5-cycloheptatriene (1), 1H-azepine (3) and oxepine (5)

\begin{tabular}{|c|c|c|c|c|c|c|}
\hline \multirow[t]{2}{*}{ Parameter $^{\mathbf{b}}$} & \multicolumn{3}{|l|}{ MNDO } & \multicolumn{3}{|l|}{$\mathrm{RHF} / \mathrm{A}^{\mathrm{c}}$} \\
\hline & 1 & 3 & 5 & 1 & 3 & 5 \\
\hline$R=r(1,6)$ & 2.546 & 2.477 & 2.399 & 2.498 & 2.490 & 2.371 \\
\hline$r(1,2)$ & 1.351 & 1.353 & 1.355 & 1.318 & 1.317 & 1.320 \\
\hline$r(2,3)$ & 1.459 & 1.462 & 1.462 & 1.485 & 1.490 & 1.490 \\
\hline$r(3,4)$ & 1.355 & 1.352 & 1.352 & 1.325 & 1.320 & 1.318 \\
\hline$r(1,7)$ & 1.503 & 1.426 & 1.369 & 1.528 & 1.450 & 1.401 \\
\hline$\theta(7,1,2)$ & 127.7 & 125.7 & 127.6 & 123.1 & 126.8 & 129.9 \\
\hline$\theta(1,2,3)$ & 127.6 & 127.9 & 127.9 & 125.6 & 127.0 & 126.3 \\
\hline$\theta(2,3,4)$ & 127.2 & 126.5 & 125.9 & 125.7 & 126.5 & 125.6 \\
\hline$\theta(6,7,1)$ & 115.7 & 120.6 & 122.4 & 109.7 & 118.2 & 115.6 \\
\hline$\theta(8,1,7)$ & 113.8 & 113.9 & 110.5 & 117.0 & 113.4 & 110.1 \\
\hline$\theta(8,1,2)$ & 118.5 & 120.2 & 121.8 & 120.0 & 119.7 & 119.9 \\
\hline$\theta(9,2,1)$ & 118.4 & 117.5 & 117.3 & 119.3 & 117.6 & 117.3 \\
\hline$\theta(9,2,3)$ & 114.1 & 114.5 & 114.8 & 115.2 & 115.3 & 116.3 \\
\hline$\theta(10,3,2)$ & 114.4 & 114.4 & 114.7 & 115.5 & 114.8 & 115.1 \\
\hline$\theta(10,3,4)$ & 118.4 & 119.0 & 119.4 & 118.8 & 118.8 & 119.3 \\
\hline$\theta(14,7,15)$ & 105.5 & - & 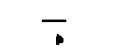 & 107.7 & - & - \\
\hline$\omega(7,1,2,3)$ & 3.2 & 4.7 & 3.9 & 3.8 & 2.6 & 4.0 \\
\hline$\omega(1,2,3,4)$ & 23.3 & 20.5 & 18.2 & 33.4 & 24.1 & 23.1 \\
\hline$\omega(2,3,4,5)$ & 0 & 0 & 0 & 0 & 0 & 0 \\
\hline$\omega(6,7,1,2)$ & 43.6 & 46.0 & 41.0 & 61.1 & 46.0 & 45.8 \\
\hline
\end{tabular}

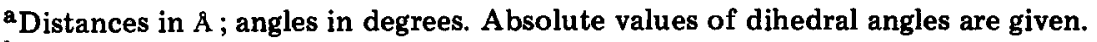

$b$ The definition of the geometrical parameters complies with numbering of atoms as shown for 1 in $\mathrm{Fig} .1$.

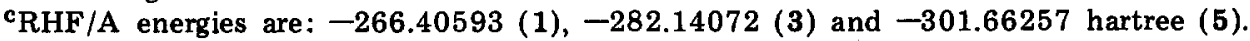
The corresponding RHF/B and RHF/C energies at RHF/A geometries are: -269.29383, $-285.24657,-305.04166(\mathrm{~B})$; and $-269.68035,-285.66221$ and -305.48456 hartree (C).

The RHF/A geometries of compounds $21-27[25,26]$ are in somewhat better accord with experimental data [27-29] than the MNDO geometries [19]. In particular, the $\mathrm{RHF} / \mathrm{A}$ description of the three-membered rings and the heavy atom bond angles of 21-24 is superior to MNDO results. On the other hand, RHF/A theory underestimates the effects of $\pi$-delocalization on the bond lengths of butadiene 24, thus predicting the double bonds too short and the single bonds too long. MNDO geometries do not show this deficiency and, hence, should provide reasonable descriptions of the geometries of conjugated polyenes.

The conclusions drawn from a comparison of the data of Table 6 can directly be applied to the analysis of the theoretical geometries of $1-6$. Thus, the overall shape of these systems is described better by RHF/A than MNDO. This is especially true for the equilibrium values of $R=r(1,6)$, which come 
TABLE 2

Theoretical geometries for norcaradiene (2), benzene imine (4) and benzene oxide (6)

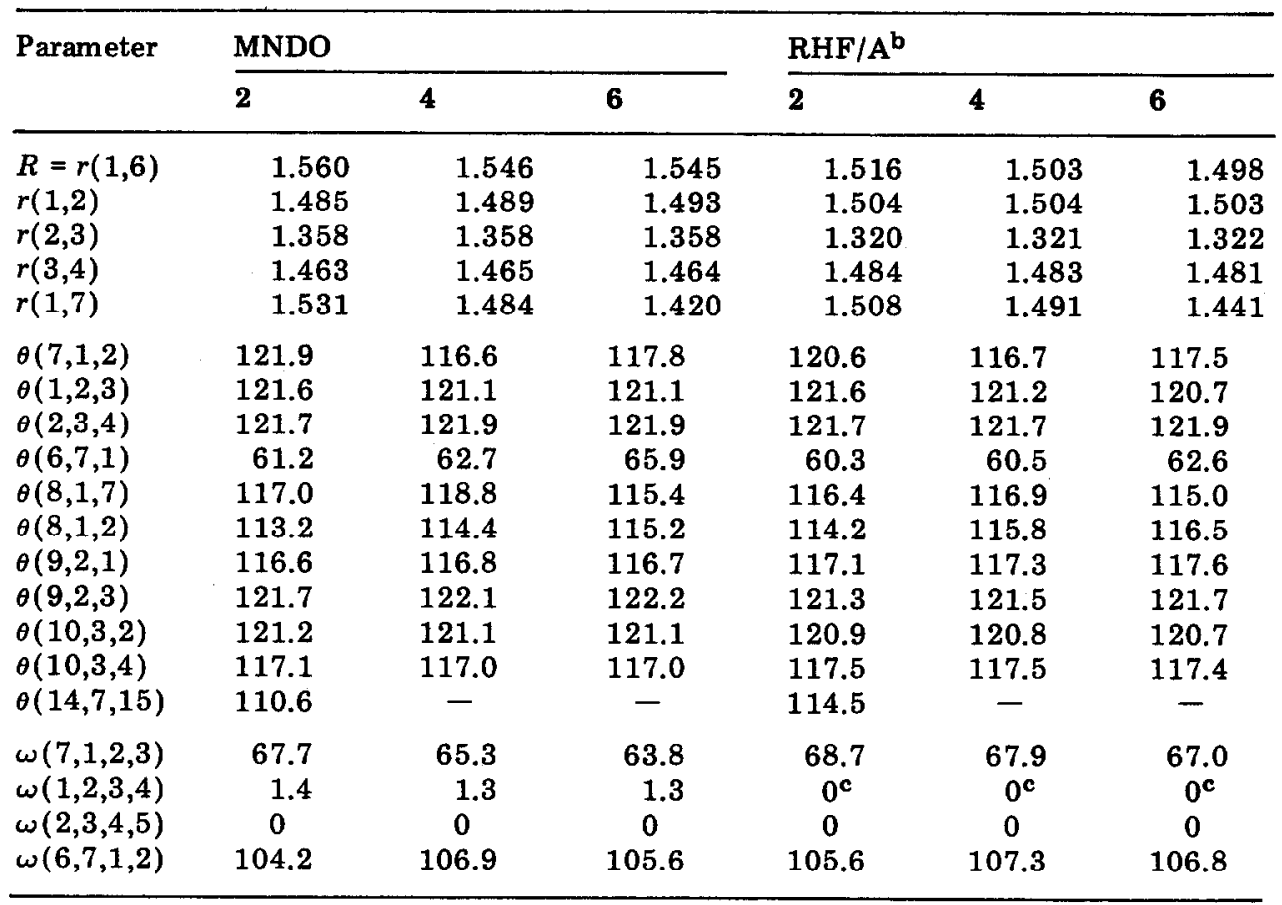

${ }^{a}$ See footnotes ${ }^{a}$ and ${ }^{b}$ of Table 1.

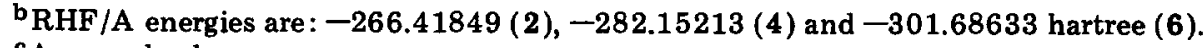

${ }^{\mathrm{c}}$ Assumed values.

out far too long when computed with MNDO. The ED bond lengths of the triene part of CHT, however, resemble more closely the corresponding MNDO values than the ab initio results. Again, bond alternation is overestimated by RHF/A theory.

A recently published RHF/B structural investigation of CHT carried out by Saeb $\phi$ and Boggs [30] is probably more reliable in this respect. The RHF/B bond lengths of the triene part $(1.325,1.455$ and $1.336 \AA[30])$ are indeed intermediate between RHF/A and MNDO values. As for the other parameters, basis $\mathrm{A}$ and basis $\mathrm{B}$ values are in good accord.

\section{Conformational features}

Both ED [4] and MW [5] measurements, have established a boat form for CHT. The values of the folding angles, $\alpha$ and $\beta$, obtained from the two experimental investigations vary considerably (Table 8). The RHF/A values of these parameters (Table 3) support the results of the MW analysis, namely $\alpha$ close to $50^{\circ}$ and $\beta$ close to $30^{\circ}$. Similar angles have been found from $\mathrm{HF} / \mathrm{B}$ 
TABLE 3

Conformational parameters of cyclotriene and norcaradiene forms derived from theoretical geometries $^{\mathbf{a}}$

\begin{tabular}{|c|c|c|c|c|c|c|c|}
\hline Molecule & $\alpha$ & $\beta$ & $\tau$ or $\tau^{\prime}$ & $\mathbf{Q}^{\mathbf{b}}$ & $q_{2}$ & $q_{3}$ & $\eta_{q}^{c}$ \\
\hline & \multicolumn{7}{|c|}{$M N D O-G e o m e t r i e s$} \\
\hline 1 & 33.9 & 18.7 & -0.5 & 0.511 & 0.488 & 0.152 & 23.6 \\
\hline 2 & 67.0 & 1.3 & 1.5 & 0.923 & 0.673 & 0.633 & 48.5 \\
\hline 3 & 36.9 & 16.4 & 46.7 & 0.470 & 0.446 & 0.148 & 22.2 \\
\hline 4 & 73.9 & 1.2 & 63.6 & 0.951 & 0.692 & 0.653 & 48.5 \\
\hline 5 & 32.5 & 14.7 & - & 0.404 & 0.387 & 0.118 & 21.8 \\
\hline \multirow[t]{2}{*}{6} & 72.9 & 1.3 & - & 0.894 & 0.650 & 0.613 & 48.5 \\
\hline & \multicolumn{7}{|c|}{ RHF/A Geometries } \\
\hline 1 & 48.6 & 27.3 & -0.7 & 0.752 & 0.718 & 0.222 & 23.6 \\
\hline 2 & 68.5 & $0^{d}$ & 0.6 & 0.918 & 0.653 & 0.644 & 49.6 \\
\hline 3 & 36.3 & 19.5 & 48.7 & 0.519 & 0.499 & 0.142 & 22.2 \\
\hline 4 & 73.3 & $0^{d}$ & 70.9 & 0.951 & 0.678 & 0.667 & 49.6 \\
\hline $\mathbf{5}$ & 34.7 & 19.1 & - & 0.507 & 0.489 & 0.136 & 21.8 \\
\hline 6 & 73.0 & $0^{\mathrm{d}}$ & - & 0.910 & 0.649 & 0.639 & 49.6 \\
\hline
\end{tabular}

${ }^{a}$ Angles in degrees, puckering amplitudes in A. See Fig. 2 for the definition of $\alpha, \beta$, and $\tau$. Puckering parameters are $q_{2}, \phi_{2}=0^{\circ}, q_{3}, \phi_{3}=0^{\circ}$.

${ }^{b} Q=\left(q_{2}^{2}+q_{3}^{2}\right)^{1 / 2}$.

cThe chair character $\eta_{q}$ (eq. 1 ) is given in percent.

$\mathbf{d}_{\beta}$ not optimized.

TABLE 4

Theoretical geometries of planar forms of compounds 1,3 , and $5^{\text {a }}$

\begin{tabular}{|c|c|c|c|c|c|c|}
\hline \multirow[t]{2}{*}{ Parameter } & \multicolumn{3}{|l|}{ MNDO } & \multicolumn{3}{|l|}{ RHF/A } \\
\hline & 1 & 3 & 5 & 1 & 3 & 5 \\
\hline$R=r(1,6)$ & 2.609 & 2.535 & 2.443 & 2.621 & 2.545 & 2.431 \\
\hline$r(1,2)$ & 1.349 & 1.352 & 1.354 & 1.316 & 1.317 & 1.319 \\
\hline$r(2,3)$ & 1.456 & 1.460 & 1.461 & 1.484 & 1.492 & 1.489 \\
\hline$r(3,4)$ & 1.354 & 1.351 & 1.350 & 1.322 & 1.318 & 1.325 \\
\hline$r(1,7)$ & 1.500 & 1.413 & 1.364 & 1.532 & 1.434 & 1.403 \\
\hline$\theta(7,1,2)$ & 131.5 & 129.1 & 130.4 & 132.6 & 130.6 & 133.9 \\
\hline$\theta(1,2,3)$ & 129.6 & 129.4 & 129.3 & 130.8 & 129.1 & 130.3 \\
\hline$\theta(2,3,4)$ & 128.5 & 127.7 & 126.7 & 127.8 & 127.7 & 125.8 \\
\hline$\theta(6,7,1)$ & 120.9 & 127.6 & 127.2 & 117.6 & 125.1 & 120.1 \\
\hline$\theta(8,1,7)$ & 111.4 & 111.4 & 108.7 & 111.3 & 110.7 & 107.3 \\
\hline$\theta(8,1,2)$ & 117.1 & 119.5 & 120.9 & 116.1 & 118.7 & 118.8 \\
\hline$\theta(9,2,1)$ & 117.2 & 116.7 & 116.4 & 116.0 & 116.3 & 114.9 \\
\hline$\theta(9,2,3)$ & 113.3 & 113.9 & 114.3 & 113.1 & 114.6 & 114.8 \\
\hline$\theta(10,3,2)$ & 113.8 & 113.9 & 114.3 & 114.1 & 114.1 & 114.9 \\
\hline$\theta(10,3,4)$ & 117.7 & 118.3 & 119.0 & 118.1 & 118.2 & 119.3 \\
\hline$\theta(14,7,15)$ & 105.6 & $27.7^{\mathrm{b}}$ & & 105.6 & $30.9^{b}$ & \\
\hline
\end{tabular}

${ }^{a}$ See footnotes ${ }^{a}$ and $^{b}$ of Table 1.

${ }^{b}$ Values of $\tau$; see Fig. 2. 
TABLE 5

Experimental geometries of CHT and some substituted cyclotrienes and norcaradienes ${ }^{\mathrm{a}}$

\begin{tabular}{llllll}
\hline Parameter & $\begin{array}{l}\text { 1 } \\
\text { ED } \\
\text { Ref. } 4\end{array}$ & $\begin{array}{l}\text { 10 } \\
\text { X-Ray } \\
\text { Ref. 8 }\end{array}$ & $\begin{array}{l}\text { 13 } \\
\text { X-Ray } \\
\text { Ref. 13 }\end{array}$ & $\begin{array}{l}\text { 15 } \\
\text { X-Ray } \\
\text { Ref. 15 }\end{array}$ & $\begin{array}{l}\text { 17 } \\
\text { X-Ray } \\
\text { Ref. 11 }\end{array}$ \\
\hline$R=r(1,6)$ & 2.511 & 2.410 & 1.501 & 1.535 & 2.426 \\
$r(1,2)$ & $1.356^{\text {b }}$ & 1.337 & 1.480 & 1.478 & 1.32 \\
$r(2,3)$ & 1.446 & 1.470 & 1.351 & 1.340 & 1.435 \\
$r(3,4)$ & $1.356^{\text {b }}$ & 1.357 & 1.452 & 1.439 & 1.34 \\
$r(1,7)$ & 1.505 & 1.496 & 1.556 & 1.530 & 1.415 \\
$\theta(7,1,2)$ & 121.8 & 122.8 & 118.0 & 119.8 & 123.5 \\
$\theta(1,2,3)$ & 127.2 & 121.3 & 118.5 & 121.2 & 127 \\
$\theta(2,3,4)$ & 119.8 & 125.0 & 122.2 & 121.9 & 125.5 \\
$\theta(6,7,1)$ & 113.1 & 108.8 & 57.7 & 60.2 & 118 \\
$\omega(7,1,2,3)$ & 22.4 & 0.5 & 66.4 & 62.6 & 2.5 \\
$\omega(1,2,3,4)$ & 54.2 & 39.8 & 4.2 & 6.7 & 28 \\
$\omega(2,3,4,5)$ & 0 & 2.5 & 0 & 0.1 & 1 \\
$\omega(6,7,1,2)$ & 44.1 & 66.2 & 108.6 & 105.2 & 54.5 \\
\hline
\end{tabular}

${ }^{a}$ Distances in $\AA$, angles in deg. In some cases, average values are given to obtain $C_{\mathbf{s}}$ symmetry.

${ }^{b}$ Assumed to be equal.

TABLE 6

Theoretical and experimental geometries of some reference compounds ${ }^{\mathrm{a}}$

\begin{tabular}{llccc}
\hline Molecule & Parameter & MNDO $^{\mathrm{b}}$ & RHF/Ac & Exp. $^{\mathrm{d}}$ \\
\hline Propane (21) & $\mathrm{R}(\mathrm{CC})$ & 1.530 & 1.541 & 1.526 \\
& $\theta(\mathrm{CCC})$ & 115.4 & 111.6 & 112.4 \\
Dimethylamine (22) & $\mathrm{R}(\mathrm{CN})$ & 1.464 & 1.477 & 1.466 \\
& $\theta(\mathrm{CNC})$ & 116.0 & 110.5 & 112.2 \\
Dimethylether (23) & $\mathrm{R}(\mathrm{CO})$ & 1.396 & 1.433 & 1.410 \\
& $\theta(\mathrm{COC})$ & 120.0 & 109.4 & 111.7 \\
trans-1,3-Butadiene (24) & $\mathrm{R}(\mathrm{C}=\mathrm{C})$ & 1.344 & 1.313 & 1.341 \\
& $\mathrm{R}(\mathrm{C}-\mathrm{C})$ & 1.465 & 1.488 & 1.463 \\
Cyclopropane (25) & $\theta(\mathrm{CCC})$ & 125.7 & 124.2 & 123.3 \\
Aziridine (26) & $\mathrm{R}(\mathrm{CC})$ & 1.525 & 1.502 & 1.510 \\
& $\mathrm{R}(\mathrm{CC})$ & 1.516 & 1.491 & 1.481 \\
& $\mathrm{R}(\mathrm{CN})$ & 1.479 & 1.482 & 1.475 \\
Oxirane (27) & $\theta(\mathrm{CNC})$ & 61.7 & 60.4 & 60.3 \\
& $\mathrm{R}(\mathrm{CC})$ & 1.513 & 1.483 & 1.471 \\
& $\mathrm{R}(\mathrm{CO})$ & 1.417 & 1.433 & 1.436 \\
& $\theta(\mathrm{COC})$ & 64.5 & 62.3 & 61.6 \\
\hline
\end{tabular}

${ }^{a}$ Bond lengths in $\AA$, angles in degrees. ${ }^{b}$ Ref. 19 . ${ }^{c} 21,22$ and 23 , this work; 24, ref. 25; 25,26 and 27 , ref. 26 . 24 , ref. $28 ; 25$, ref. 29 ; all other data from ref. 27. 
calculations [30], a molecular mechanics study of CHT [31] and x-ray investigations of CHTs 8-12 [6-9]. The MNDO calculations lead to smaller angles but also predict $\alpha>\beta$ contrary to the ED results of Traetteberg [4] .

One further piece of evidence relevant in this respect is provided by the measured moments of inertia of CHT [5]. These are compared in Table 7 with the corresponding ab initio and MNDO values. RHF/A values agree well with the MW data thus giving further support to the MW values of $\alpha$ and $\beta$. The semiempirical moments of inertia are less accurate, which suggest that MNDO underestimates puckering of 1 .

According to theory, AZP and OXP possess somewhat flattened boat forms. Crystallographic data on substituted AZPs [10-12] are in line with this description. A previous RHF/A investigation of 5, however, suggests planarity for oxepine [32]. These calculations have been performed for a constrained geometric model leading to a RHF/A total energy of 5 about 10 mhartree higher than our value. Since 5 possesses a rather small barrier to planarity, it is likely that the nonplanar minimum has not been found with the geometry model of ref. 32 .

In order to get a better understanding of the conformational features of the three cyclotrienes, the calculated puckering amplitudes $q_{2}$ and $q_{3}$ are compared in Table 3 . In fact, the boat form prevails in the conformations of 1,3 and 5 . However, this description is incomplete as the computed conformations possess, in addition, some chair character.

We calculated an admixture of $22.5 \pm 1 \%$ chair character to the boat form of the three cyclotrienes (Table 3 and Fig. 2). Thus, the mode of puckering is constant for the three cyclotrienes. This is also suggested by the MW analysis of 1 [5] and the available X-ray data of compounds 8-12 and 16-18 (Table 8). An average value of $23 \%$ chair character is obtained from their puckering amplitudes. On the background of these data it becomes obvious that $\eta_{q}<0$ for CHT is erroneous (Table 8).

While the mode of puckering is constant for three cyclotrienes, the total degree of puckering measured by $Q$ decreases in the series $1,3,5$ (Table 3 ). By comparing calculated $Q$ values, it becomes obvious that MNDO underestimates puckering by about $30 \%(1), 9 \%(3)$ and $20 \%(5)$. RHF/A values of $Q$ are closer to reality. Nevertheless, they still seem somewhat small when

\section{TABLE 7}

Experimental and theoretical moments of inertia $I$ for $1,3,5$-cycloheptatriene ${ }^{a}$

\begin{tabular}{lllll}
\hline Method & $I_{a}$ & $I_{b}$ & $I_{c}$ & Ref. \\
\hline Microwave & 136.77 & 137.67 & 248.75 & 5 \\
Ab initio & 138.00 & 138.53 & 252.64 & this work \\
MNDO & 139.30 & 142.94 & 269.27 & this work \\
\hline
\end{tabular}

${ }^{a} I$ in atomic mass units $X \mathrm{~A}^{2}$. 
compared with experimental amplitudes $Q$ (Table 8). Actually this is not surprising in view of the results obtained with RHF/A theory for other puckered rings [33-35]. The stiffness of the minimal basis causes an overestimation of angle strain and thus leads to smaller $Q$ values.

Similar conclusions hold for the conformational features of the bicyclic forms. The RHF/A and MNDO puckering amplitudes are now in reasonable agreement. Probably, this reflects the loss of conformational flexibility when forming the bond $\mathrm{C}_{1}-\mathrm{C}_{6}$. The influence of the heteroatoms on the degree of puckering has vanished. The rather small values of $\beta$ obtained with MNDO indicate that the assumption of $\beta=0^{\circ}$ is a reasonable simplification. The NCD conformation can be considered as a 1:1 mixture of boat and chair form (Table 3 and Fig. 2).

The $\mathrm{CH}_{2}$ group is tilted slightly inward in 1 , but outward in 2 . This was also found by Saeb $\phi$ and Boggs [30]. It is interesting to note that pyramidalization at $\mathrm{N}$ measured by $\tau$ increases considerably when going from 3 to 4 . This corresponds to a widening of the $\mathrm{HCH}$ angle from $107.7(1)$ to $114.5^{\circ}$ (2) (RHF/A, Table 3) and reveals considerable rehybridization at atom 7 during valence tautomerization.

\section{Barriers to inversion}

At the RHF/A level of theory the barriers to ring inversion of 1, 3 and 5 are $3.7,2.5$ and $1.6 \mathrm{kcal} \mathrm{mol}^{-1}$. For CHT the RHF/A barrier is about $2 \mathrm{kcal}$

\section{TABLE 8}

Conformations of some cycloheptatrienes and norcaradienes as obtained from experimental measurements $^{\mathbf{a}}$

\begin{tabular}{|c|c|c|c|c|c|c|c|c|c|}
\hline Molecule & Method & $\alpha$ & $\beta$ & $\eta_{\alpha} 100$ & $q_{2}$ & $q_{3}$ & $\boldsymbol{Q}$ & $\eta_{q} \times 100$ & Ref. \\
\hline 1 & ED & 36.5 & 40.5 & -5 & 0.816 & 0.070 & 0.819 & -8 & 4 \\
\hline 1 & MW & 50 & 29.5 & 20 & 0.77 & 0.23 & 0.80 & 23 & 5 \\
\hline 8 & & 47.9 & 24.4 & 25 & 0.685 & 0.246 & 0.728 & 26 & 6 \\
\hline 9 & & 45.7 & 28.8 & 18 & 0.674 & 0.178 & 0.697 & 21 & 7 \\
\hline 10 & & 52.6 & 34.3 & 17 & 0.815 & 0.200 & 0.839 & 20 & 8 \\
\hline 11 & & 43.5 & 34.8 & 10 & 0.791 & 0.255 & 0.831 & 24 & 9 \\
\hline 12 & & 28 & 23 & 9 & 0.674 & 0.271 & 0.727 & 29 & 9 \\
\hline 13 & & 71.9 & 4.2 & 47 & 0.762 & 0.671 & 1.016 & 47 & 13 \\
\hline 14 & X-Ray & 68.5 & 7.0 & 45 & 0.761 & 0.627 & 0.986 & 45 & 14 \\
\hline 15 & & 68.9 & 6.4 & 45 & 0.753 & 0.628 & 0.981 & 45 & 15 \\
\hline 16 & & 52 & 28 & 23 & 0.688 & 0.183 & 0.711 & 21 & 10 \\
\hline 17 & & 44.3 & 22.5 & 25 & 0.566 & 0.165 & 0.589 & 23 & 11 \\
\hline 18 & & 59.3 & 28.8 & 26 & 0.730 & 0.213 & 0.760 & 23 & 12 \\
\hline 19 & & 105.0 & 1.7 & 49 & 0.670 & 0.654 & 0.937 & 49 & 16 \\
\hline 20 & & 102.9 & 1.2 & 49 & & & & & 17 \\
\hline
\end{tabular}

${ }^{a}$ Angles in degrees, puckering amplitudes in $A$, chair character $\eta$ in percent. $\eta_{\alpha}=(\alpha-\beta) /$ $2 \alpha$. For X-ray structures eq. 1 has been simplified to $\eta_{q}=q_{3} /\left(q_{2}+q_{3}\right)$. Puckering parameters have been calculated from experimental coordinates. 
$\mathrm{mol}^{-1}$ smaller than the experimental value of $6 \mathrm{kcal} \mathrm{mol}^{-1}$ [36]. With RHF/B calculations a slightly improved barrier value of $5 \mathrm{kcal} \mathrm{mol}^{-1}$ is obtained, which has to be compared with the corresponding value of Saeb $\phi$ and Boggs $\left(5.7 \mathrm{kcal} \mathrm{mol}^{-1}[30]\right)$. A better account of the barrier should be achieved at the RHF/C level of theory [33-35]. The calculated inversion barriers (4 (1), 1.7 (3), $\left.1.5 \mathrm{kcal} \mathrm{mol}^{-1}(5)\right)$, however, are lower than expected, which is probably a consequence of the use of the RHF/A geometries. Taking into consideration all calculated values and the deficiencies of basis $A$, inversion barriers of about $6(1), 3(3)$ and $2 \mathrm{kcal} \mathrm{mol}^{-1}(5)$ can be predicted for the three cyclotrienes.

The geometries of the planar forms of 1, 3 and 5 (see Table 4) differ from those of the puckered forms only with regard to their angles. The bond distances are almost the same, which suggests that the same electronic effects are operative in the puckered and planar forms. In this connection it is also informative to calculate the barrier to nitrogen inversion. For puckered AZP it is larger than the barrier to ring inversion, but decreases to just $0.2 \mathrm{kcal}$ $\mathrm{mol}^{-1}$ (RHF/A) when AZP becomes planar. This indicates that inversion at the pyramidal $\mathrm{N}$ atom is coupled to ring inversion. The transition state for $\mathrm{N}$ inversion is characterized by the relative energy of a totally planar AZP with a $s p^{2}$-hybridized $\mathrm{N}$ atom. Puckered AZP possessing either an $s p^{2}$-hybridized $\mathrm{N}$ atom or an $\mathrm{NH}$ bond in an axial position is not stable. If the AZP ring inverts, inversion at the $\mathrm{N}$ atom takes also place in order to guarantee that the NH bond remains always in the equatorial position. Similar observations have been made for azetidine [35].

\section{DISCUSSION}

The calculated structural and conformational features of compounds 1-6 should be indicative of the electronic effects operative in these systems. Thus, the degree of bond alternation, the magnitude of the distance $R$, the amount of angle and torsional strain, the geometries of the planar forms, and the barriers to inversion have to be analyzed to determine whether delocalization of $\pi$-electrons leads to a nonaromatic (polyenic), homoaromatic or antiaromatic character for these molecules.

Despite the nonplanar character of $1-6$, bond alternation is typical for a planar polyene such as trans-1,3-butadiene (Table 6) and is definitely larger than for a homoaromatic $6 \pi$-system [37]. Bond alternation does not depend on the distance $R$. Thus, replacement of $\mathrm{CH}_{2}$ by NH or O leads to negligible changes of the triene bond lengths. When going from the planar to the puckered forms of 1,3 and 5 the distance $R$ decreases by 0.06 to $0.10 \AA$, which is equivalent to a 4 to $8^{\circ}$ decrease of the CXC angle. At the same time, the degree of bond alternation remains constant. Puckering reduces the sum of internal ring angles by $42(1), 21$ (3) and $21^{\circ}(5)$, suggesting a significant reduction of angle strain caused by angle widening in the planar forms (Table 4). In the same way torsional strain is reduced in the puckered forms. 
Eclipsing of $\mathrm{CH}$ bonds is lowered by $20-30^{\circ}$ (Table 1 ). These data comply with the calculated barriers. Neither geometries nor inversion barriers provide any evidence for homoaromatic $6 \pi$-delocalization in CHT, AZP or OXP.

Antiaromatic $8 \pi$-interactions, if present, should be more important in the planar than the puckered forms, in planar 5 more than in planar 3 or 1 , in AZP with an $s p^{2}$-hybridized $\mathrm{N}$ more than in normal AZP. This means that the various inversion barriers should reflect the degree of antiaromatic interactions. The computed trend in the barrier values is contrary to expectations based on the hypothesis of $8 \pi$-electron delocalization. In particular, the data for AZP and OXP suggest that puckering is not caused by antiaromatic $8 \pi$ electron interactions in the planar forms.

These conclusions, however, do not exclude the possibility that the thermochemical properties of 1,3 and 5 may be exceptional when compared with seven-membered cyclodienes or cycloenes. In this connection consideration of the actual conformation of the three cyclotrienes is of importance. The constant admixture of chair character to the boat forms of 1,3 and 5 leads to a flattening of the triene part, which in turn increases $\pi$-electron delocalization. Compared to an ideal boat form with $\alpha=\beta$ (or $q_{3}=0$ ) the observed conformations are stabilized. Hence, it is appropriate to describe 1, 3 and 5 as cyclopolyenes with weak but not homoaromatic 1,6 interactions, which are stabilized by a favorable compromise between ring puckering (relief of strain) and $\pi$-electron delocalization in the triene part.

As for the NCD forms, interactions between $\pi$ - and Walsh-MOs would be largest for a parallel alignment of orbitals at $\alpha=90^{\circ}$ and $\beta=0^{\circ}$. In 2,4 and $6 \alpha$ approaches this value by 22,17 and $17^{\circ}$, while $\beta$ is close to $0^{\circ}$ for all compounds considered. Again, the observed degree of bond alternation is typical for a cyclopolyene without aromatic $6 \pi$-delocalization. On the other hand, there is a significant increase of $r(1,6)$ relative to the corresponding values of the reference compounds 25,26 and $27(0.014(2), 0.021(4)$ and $0.015 \AA(6)$; see Tables 2 and 6). In addition, the bond lengths $r(1,2)$ and $r(5,6)$ are $0.02 \AA$ smaller than $1.52 \AA$, the standard CC bond length between an $s p^{2}$ - and $s p^{3}$-hybridized $C$ atom [14]. These observations suggest that the three-membered ring interacts in some way with the diene fragment, thus leading to some (weak) $\pi$-character of the 1,6 bond. We conclude that homoaromatic delocalization of $6 \pi$-electrons cannot be excluded in the case of NCD, BI and BO. The structural information presented here, however, does not suffice to prove homoaromaticity for the NCD forms. Work is in progress to deal with this question, which is of considerable importance in view of a recent claim that homoaromaticity does not occur in neutral molecules [38].

\section{CONCLUSIONS}

The following conclusions can be drawn from the present work. (1) CHT, AZP and OXP possess boat conformations with a constant admixture of $22 \%$ chair character to the boat form. (2) As a consequence of the partial chair 
character and the corresponding flattening of the triene part, $\pi$-electron delocalization in 1, 3 and 5 is comparable to that of a planar polyene, thus leading to some stabilization of the three cyclotrienes. (3) CHT, AZP and OXP are not homoaromatic. Their structures are fully understandable in terms of angle strain (leading to puckering) and torsional strain (causing the differences in puckering 1,3 and 5 ). (4) The barriers for inversion are about $6(1), 3(3)$ and $2 \mathrm{kcal} \mathrm{mol}^{-1}(5)$. They are a consequence of increased ring strain rather than destabilizing $8 \pi$-electron delocalization. (5) There are considerable interactions between $\pi$ - and Walsh-MOs in the NCD forms 2, 4 and 6, which may eventually lead to homoaromatic character.

\section{ACKNOWLEDGEMENT}

We thank Dr. E. Kraka for carrying out some of the calculations presented here. This work was supported by the Deutsche Forschungsgemeinschaft and the Fonds der Chemischen Industrie. All calculations were performed at the Regionales Rechenzentrum Köln, utilizing a CDC CYBER 76.

\section{REFERENCES}

1 G. Maier, Angew. Chem., 79 (1967) 446; W. Tochtermann, Topics Curr. Chem., 15 (1970) 378; H. Kessler, in Methoden der Organischen Chemie, Houben-Weyl-Müller, Vol. V/1d, 4th edn., G. Thieme Verlag, Stuttgart, 1972, p. 305.

2 L. A. Paquette, in J. P. Snyder (Ed.), Nonbenzenoid Aromatics, Academic Press, New York, 1969, Vol. 1, p. 249; L. A. Paquette, Angew. Chem., 83 (1971) 11; E. Vogel, H.-J. Altenbach, J. M. Drossard, H. Schmickler and H. Stegelmeier, Angew. Chem., 92 (1980) 1053.

3 E. Vogel and H. Günther, Angew. Chem., 79 (1967) 429.

4 M. Traetteberg, J. Am. Chem. Soc., 86 (1964) 4265.

5 S. S. Butcher, J. Chem. Phys., 42 (1965) 1833.

6 R. E. Davis and A. Tulinsky, J. Am. Chem. Soc., 88 (1966) 4583.

7 J. E. Weidenborner, R. B. Larrabee and A. L. Bednowitz, J. Am. Chem. Soc., 94 (1972) 4140.

8 J. Stegemann and H. J. Lindner, Acta Crystallogr., Sect. B, 35 (1979) 2161.

9 W. Bauer, J. Daub, G. Maas, M. Michna, K. M. Rapp and J. J. Stezowski, Chem. Ber., 115 (1982) 99.

10 J. C. Paul, S. M. Johnson, L. A. Paquette, J. H. Barrett and R. J. Haluska, J. Am. Chem. Soc., 90 (1968) 5023.

11 H. J. Lindner and B. v. Gross, Chem. Ber., 105 (1972) 434.

12 H. H. Eckhardt, D. Hege, W. Massa, H. Perst and R. Schmidt, Angew. Chem., 93 (1981) 713.

13 C. J. Fritchie, Acta Crystallogr., 20 (1966) 27.

14 W. Dreissig, P. Luger, D. Rewicki and C. Tuchscherer, Cryst. Struct. Commun., 2 (1973) 197.

15 G. Maas, K. Fischer and M. Regitz, Acta Crystallogr., Sect. B, 30 (1974) 1140.

16 B. Epe, P. Rösner and W. Tochtermann, Justus Liebigs Ann. Chem., (1980) 1889.

17 J. P. Glusker, D. E. Zacharias, H. L. Carrell, P. P. Fu and R. G. Harvey, Cancer Res., 36 (1976) 3951.

18 D. Cremer, J. Am. Chem. Soc., submitted. 
19 M. J. S. Dewar and W. Thiel, J. Am. Chem. Soc., 99 (1977) 4899; 4907.

20 W. Thiel, J. Am. Chem. Soc., 103 (1981) 1420.

21 W. J. Hehre, R. F. Stewart and J. A. Pople, J. Chem. Phys., 51 (1969) 2657; R. Ditchfield, W. J. Hehre and J. A. Pople, J. Chem. Phys., 54 (1971) 724 ; P. C. Hariharan and J. A. Pople, Theor. Chim. Acta, 28 (1973) 213.

22 J. A. Pople and M. S. Gordon, J. Am. Chem. Soc., 89 (1967) 4253.

23 D. Cremer and J. A. Pople, J. Am. Chem. Soc., 97 (1975) 1354.

24 D. Cremer, Isr. J. Chem., 20 (1979) 12.

25 W. J. Hehre and J. A. Pople, J. Am. Chem. Soc., 97 (1975) 6941.

26 W. A. Lathan, L. Radom, P. C. Hariharan, W. J. Hehre and J. A. Pople, Topics Curr. Chem., 40 (1973) 1.

27 W. Gordy and R. L. Cook, Microwave Molecular Spectra, Wiley Interscience, New York, 1970.

28 A. Almenningen, O. Bastiansen and M. Traetteberg, Acta Chem. Scand., 12 (1958) 1221.

29 O. Bastiansen, F. N. Fritsch, K. Hedberg, Acta Crystallogr., 17 (1964) 538.

30 S. Saeb $\phi$ and J. E. Boggs, J. Mol. Struct., 87 (1982) 365.

31 N. L. Allinger and J. T. Sprague, J. Am. Chem. Soc., 95 (1973) 3893 ; J. Kao and N. L. Allinger, J. Am. Chem. Soc., 99 (1977) 935.

32 D. Hayes, S. D. Nelson, W. A. Garland and P. A. Kollman, J. Am. Chem. Soc., 102 (1980) 1255.

33 D. Cremer and J. A. Pople, J. Am. Chem. Soc., 97 (1975) 1358.

34 D. Cremer, J. Am. Chem. Soc., 99 (1977) 1307.

35 D. Cremer, O. V. Dorofeeva and V. S. Mastryukov, J. Mol. Struct., 75 (1981) 225.

36 F. A. L. Anet, J. Am. Chem. Soc., 86 (1964) 458; F. R. Jensen and L. A. Smith, J. Am. Chem. Soc., 86 (1964) 956.

37 D. Cremer, E. Kraka, T. S. Slee, R. F. W. Bader, C. D. H. Lau and T. T. Nguyen-Dang, J. Am. Chem. Soc., 105 (1983) 5069.

38 K. N. Houk, R. W. Gandour, R. W. Strozier, N. G. Rondan and L. A. Paquette, J. Am. Chem. Soc., 101 (1979) 6797. 